\title{
Estimating incidence and prevalence of treated psychiatric disorders from routine statistics: the example of schizophrenia in Oxfordshire
}

\author{
Michael Goldacre, Raj Shiwach, David Yeates
}

\begin{abstract}
Study objective - To use routine statistical records to estimate the incidence and prevalence of treated schizophrenia.

Design and setting - Analysis of linked records in Oxfordshire (population 540000 ) for all people in contact with specialist psychiatric services from 197586.

Subjects - Records of 685 people with a diagnosis of schizophrenia as an inpatient and a further 294 people who received specialist psychiatric care for schizophrenia outside hospital without any record of inpatient care.
\end{abstract}

Measurements and main results - The measures most commonly recorded in psychiatric statistics, first admission rates for people in whom schizophrenia was recorded at their first psychiatric admission, were 8.7 per 100000 males and 5.6 per 100000 females. First contact rates for people in whom schizophrenia was recorded at any time in the study period and in any setting were $15 \cdot 1$ per 100000 males and 11.4 per 100000 females. Whichever patient population was analysed, the broad profile of schizophrenia by age, sex, and calendar time was similar.

Conclusions - First admission rates for schizophrenia, as identifiable in current routine information systems, are useful indicators of the general pattern of disease but are inadequate absolute indicators of treated incidence. These data are limited to the first ever contact. Reliable information about the treated incidence of disease requires information systems which incorporate information about when and where each diagnosis was first made. Reliable information about treated prevalence requires systems which also incorporate data about death, recovery, and migration into and out of the study population.

(f Epidemiol Community Health 1994;48:318-322)

Routine hospital information systems in England, such as the Mental Health Enquiry and local hospital episode systems, ${ }^{1-3}$ include statistical information about the use of psychiatric inpatient care. Their data are not routinely linked to provide sequential information about first and successive admissions experienced by each individual. They have, however, com- monly included a code to denote whether each psychiatric inpatient admission is the individual's first ever admission to a psychiatric hospital. This is intended to help investigators estimate the treated incidence of psychiatric disease requiring hospital admission. For specific diseases, this information is limited by the fact that the diagnosis of interest may not be the diagnosis recorded at the individual's first ever episode of psychiatric care. There is a distinction to make between, for example, a person's first ever psychiatric admission with schizophrenia as the diagnosis recorded at that time; and a person's first ever admission for schizophrenia when the diagnosis is first recorded at an admission after the person's first ever psychiatric inpatient admission. The importance of this is that first admission rates to hospital for schizophrenia, defined in the former way, despite their limitations, ${ }^{4-7}$ are often used as the best available estimates of the incidence of the disorder.

We used record linkage to analyse population based admission rates for schizophrenia, distinguishing whether the inpatient episode was the first recorded or a subsequent psychiatric admission, and to analyse population based incidence and prevalence rates of people treated for schizophrenia with or without inpatient care. The aim of this was to complement the routinely available data on schizophrenia (that enumerating first ever admissions recorded as schizophrenia) with information about subsequent admissions and care other than as an inpatient to determine the extent that the latter data add to the population based profile of schizophrenia. We report on, compare, and discuss the measures obtained.

\section{Method}

The Oxford Record Linkage Study (ORLS) includes statistical abstracts of records of hospital inpatient care, including psychiatric care, which are collected in such a way that successive records for the same person are linked together. ${ }^{8-9}$ The data are anonymised for analysis. They do not include a data item specifying whether each contact is the person's first ever psychiatric contact. Data collection for inpatient psychiatry began in part of the county of Oxfordshire in 1963 and expanded to cover the whole of Oxfordshire in 1966. Data including specialist care in psychiatry other than as an inpatient - that is outpatient care, day patient care, ward liaison care, and domiciliary visits - have been recorded since 1974. During the study period, data collection 
in psychiatry was undertaken by a team of psychiatric record clerks who were specially funded and trained to abstract and code clinical data from psychiatric casenotes and summaries completed by psychiatrists.

The ORLS clerks worked as an integral part of the medical records function as follows. ${ }^{10}$ Staff in the medical records department in each psychiatric hospital raised a new set of documentation for each new inpatient, each new course of outpatient care, and each new course of day care. The ORLS clerks visited the medical records department each day, and, after consulting the lists of new patients, initiated the completion of a three part form. The first part, completed then, contained various administrative details of the admission or appointment. The second part included social and family details and was completed by interviewing the patient. The third part, completed at the end of the course of care, was a discharge form which included the patient's diagnosis. The set of forms was used as an integral part of the medical record and a copy was sent to the ORLS. All requests from general practitioners for domiciliary visits, or from hospital clinicians to the duty psychiatrist for a ward liaison visit, were routed through the medical records department where a single part record was completed, copied for the ORLS, and placed in the medical record. The ORLS clerks checked in the medical records department for records of new patients or new courses of care on a daily basis. The diagnostic part of each form was completed, as part of the medical record, by the psychiatrist. Any forms on which the diagnosis was missing were completed in this respect by a research psychologist from the ORLS after studying the medical records to identify the diagnosis recorded by the psychiatrist.

All people resident in the county (population 540000 in 1986) who had a first recorded event of psychiatric care from 1975-86 were included in this study, except those who had

Table 1 Patients with an inpatient record which specified schizophrenia: number of psychiatric admissions per person, and admission in which schizophrenia was first recorded

\begin{tabular}{|c|c|c|c|c|c|}
\hline \multirow{2}{*}{$\begin{array}{l}\text { Inpatient record in } \\
\text { sequence with first } \\
\text { mention of schizophrenia }\end{array}$} & \multicolumn{4}{|c|}{$\begin{array}{l}\text { No of psychiatric admissions } \\
\text { per person (any diagnosis) }\end{array}$} & \multirow{2}{*}{$\begin{array}{l}\text { All people } \\
\text { No }(\%)\end{array}$} \\
\hline & 1 & 2 & 3 & $\geqslant 4$ & \\
\hline $\begin{array}{l}\text { First admission } \\
\text { Second admission } \\
\text { Third admission } \\
\text { Fourth or later }\end{array}$ & $\begin{array}{l}303 \\
- \\
-\end{array}$ & $\begin{array}{l}93 \\
52 \\
- \\
-\end{array}$ & $\begin{array}{l}48 \\
21 \\
16 \\
-\end{array}$ & $\begin{array}{l}83 \\
28 \\
16 \\
25\end{array}$ & $\begin{array}{c}527(76 \cdot 9) \\
101(14 \cdot 7) \\
32(4 \cdot 7) \\
25(3 \cdot 6)\end{array}$ \\
\hline Total & 303 & 145 & 85 & 152 & $685(100 \cdot 0)$ \\
\hline
\end{tabular}

Table 2 Number of people with schizophrenia recorded at the first inpatient admission (1st), at any inpatient admission (Any), and percentage of people in whom schizophrenia was recorded at the first admission

\begin{tabular}{|c|c|c|c|c|c|c|}
\hline \multirow[b]{2}{*}{ Age group } & \multicolumn{3}{|c|}{ Male } & \multicolumn{3}{|c|}{ Female } \\
\hline & $1 s t$ & Any & $(\%)$ & $\overline{1 s t}$ & Any & $(\%)$ \\
\hline $\begin{array}{l}<25 \\
25-34 \\
35-44 \\
45 \leqslant\end{array}$ & $\begin{array}{r}137 \\
95 \\
44 \\
43\end{array}$ & $\begin{array}{r}164 \\
109 \\
53 \\
55\end{array}$ & $\begin{array}{l}(83 \cdot 5) \\
(87 \cdot 2) \\
(83 \cdot 0) \\
(78 \cdot 2)\end{array}$ & $\begin{array}{l}60 \\
48 \\
37 \\
58\end{array}$ & $\begin{array}{l}79 \\
73 \\
61 \\
85\end{array}$ & $\begin{array}{l}(75 \cdot 9) \\
(65 \cdot 8) \\
(60 \cdot 7) \\
(68 \cdot 2)\end{array}$ \\
\hline Total & 319 & 381 & $(83.7)$ & 203 & 298 & $(68 \cdot 1)$ \\
\hline
\end{tabular}

Excludes 6 patients with age and/or sex unrecorded. any record of psychiatric care before 1975 This means that we excluded all people who had a previous record of inpatient care in the county for at least 10 years previously and all people who had a record of psychiatric care, other than as an inpatient, in the previous year.

We then used statistical abstracts of the linked records to enumerate all people who had contact with the psychiatric services for schizophrenia (code 300 in the 7 th revision of the International Classification of Diseases; 295 in the 8 th and 9 th revisions $)^{11-12}$ in any position on the list of diagnoses on the clinical abstract. We used the following measures and terms. People whose first admission for schizophrenia was also their first recorded psychiatric admission were termed people with "schizophrenia at first admission". People whose first admission recorded as schizophrenia was at an admission after their first psychiatric admission were added to the "first admissions" and the combined group was termed people with "schizophrenia at any admission". Finally, there were people whose only contacts with the psychiatric service for schizophrenia were on a non-inpatient basis: taken with the two inpatient groups, we termed the combined group as people with first recorded episodes at "any contact".

The point prevalence of treated schizophrenia was calculated as all people resident in the county and alive on 31 December 1986 who had (a) been treated in the previous year, and (b) been treated in the previous five years. This calculation included contacts in these periods for people whose first ever recorded treatment was at any time between 1963-86. Period prevalence was calculated as above except that patients who had died in the year (a) or five years (b) were also included.

\section{Results}

INCIDENCE OF TREATED SCHIZOPHRENIA

Between 1975-86, excluding people with recorded psychiatric treatment before 1975, there were 685 residents of the county with inpatient records which included a diagnosis of schizophrenia. Of these, $303(44 \cdot 2 \%)$ had only one recorded inpatient admission (table 1). A further 382 people had more than one inpatient admission of whom 158 had schizophrenia first recorded at an admission after their first psychiatric hospital admission. This represented $23.1 \%$ (158 of 685 ) of the total study population with schizophrenia and $41.4 \%$ (158 of 382 ) of the population admitted to hospital more than once.

Schizophrenia was recorded more commonly at the first inpatient episode for males than females in each age group (table 2). Overall, the diagnosis was on the first psychiatric inpatient record for 319 of 381 males (83.7\%) and 203 of 298 females $\left(68.1 \% ; \chi^{2}\right.$, comparing males and females, $22.4,1 \mathrm{df} ; \mathrm{p}<0.01$ ). Considering the 158 patients in whom the main diagnosis on the first inpatient record was not schizophrenia, the diagnosis on the record at first admission was affective psychosis for 26 people $(16.5 \%)$, paranoid states for 23 
Table 3 Treated incidence rates per annum per 100000 people in each age-sex group (and total numbers of people in all years) tabulated according to whether schizophrenia was (a) first recorded at the first hospital episode, (b) first recorded at the first and/or a subsequent hospital episode, or (c) first recorded at any contact with specialist psychiatric care

\begin{tabular}{|c|c|c|c|c|c|c|c|c|}
\hline & & \multicolumn{7}{|c|}{ Age group } \\
\hline & & $<15$ & $15-24$ & $25-34$ & $35-44$ & $45-64$ & $65<$ & Total \\
\hline $\begin{array}{l}\text { Males } \\
\text { (a) } \\
\text { (b) } \\
\text { (c) }\end{array}$ & $\begin{array}{l}\text { First admission } \\
\text { Any admission } \\
\text { Any contact }\end{array}$ & $\begin{array}{l}1.2(9) \\
1.4(11) \\
1 \cdot 7(13)\end{array}$ & $\begin{array}{l}16 \cdot 5(128) \\
19 \cdot 7(153) \\
25 \cdot 6(199)\end{array}$ & $\begin{array}{l}16 \cdot 8(95) \\
19 \cdot 3(109) \\
29 \cdot 4(167)\end{array}$ & $\begin{array}{c}9.4(44) \\
11.4(53)) \\
18.9(88)\end{array}$ & $\begin{array}{r}5.4(39) \\
6 \cdot 6(48) \\
10 \cdot 3(75)\end{array}$ & $\begin{array}{l}1 \cdot 1(4) \\
1 \cdot 8(7) \\
4 \cdot 3(16)\end{array}$ & $\begin{array}{r}8 \cdot 7(319) \\
10 \cdot 3(381) \\
15 \cdot 1(558)\end{array}$ \\
\hline $\begin{array}{l}\text { Female } \\
\text { (a) } \\
\text { (b) } \\
\text { (c) }\end{array}$ & $\begin{array}{l}\text { s: } \\
\text { First admission } \\
\text { Any admission } \\
\text { Any contact }\end{array}$ & $\begin{array}{l}0.6(4) \\
0 \cdot 8(6) \\
1 \cdot 1(8)\end{array}$ & $\begin{array}{r}8.7(56) \\
11.3(73) \\
13.8(89)\end{array}$ & $\begin{array}{c}9 \cdot 0(48) \\
13 \cdot 6(73) \\
19 \cdot 7(107)\end{array}$ & $\begin{array}{r}8 \cdot 3(37) \\
13 \cdot 6(61) \\
17 \cdot 4(78)\end{array}$ & $\begin{array}{r}6 \cdot 0(44) \\
8.4(62) \\
13 \cdot 3(98)\end{array}$ & $\begin{array}{l}2.6(14) \\
4.3(23) \\
6.5(35)\end{array}$ & $\begin{array}{r}5 \cdot 6(203) \\
8 \cdot 2(298) \\
11 \cdot 4(415)\end{array}$ \\
\hline
\end{tabular}

Excludes 6 people with age and/or sex unrecorded.

Table 4 Prevalence of treated schizophrenia: rates per 100000 people tabulated as (a) point prevalence of people treated in the previous year and (b) point prevalence of people treated in the previous five years (and numbers on which rates are based)

\begin{tabular}{|c|c|c|c|c|c|c|c|c|}
\hline & & \multicolumn{7}{|c|}{ Age group } \\
\hline & & $\leqslant 15$ & $15-24$ & $25-34$ & $35-44$ & $45-64$ & $65 \leqslant$ & Total \\
\hline $\begin{array}{l}\text { Males: } \\
\text { (a) } \\
\text { (b) }\end{array}$ & $\begin{array}{l}1 \mathrm{y} \text { point } \\
5 \text { y point }\end{array}$ & $\begin{array}{l}(0) \\
(0)\end{array}$ & $\begin{array}{r}45.9(27) \\
127.6(75)\end{array}$ & $\begin{array}{l}112 \cdot 7(46) \\
345 \cdot 6(141)\end{array}$ & $\begin{array}{l}134.6(49) \\
381.9(139)\end{array}$ & $\begin{array}{c}69 \cdot 6(36) \\
232 \cdot 1(120)\end{array}$ & $\begin{array}{r}41 \cdot 5(12) \\
117 \cdot 6(34)\end{array}$ & $\begin{array}{r}63.0(170) \\
188.5(509)\end{array}$ \\
\hline $\begin{array}{l}\text { Femal } \\
\text { (a) } \\
\text { (b) }\end{array}$ & $\begin{array}{l}1 \text { y point } \\
5 \text { y point }\end{array}$ & $\begin{array}{l}(0) \\
(0)\end{array}$ & $\begin{array}{l}33 \cdot 0(16) \\
76 \cdot 3(37)\end{array}$ & $\begin{array}{r}57 \cdot 4(24) \\
189 \cdot 0(79)\end{array}$ & $\begin{aligned} 88.9 & (33) \\
274.9 & (102)\end{aligned}$ & $\begin{array}{l}112 \cdot 0(44) \\
343 \cdot 5(135)\end{array}$ & $\begin{array}{r}39 \cdot 3(16) \\
167 \cdot 1(68)\end{array}$ & $\begin{array}{r}51.8(133) \\
163.8(421)\end{array}$ \\
\hline
\end{tabular}

$(14.6 \%)$, other psychotic illnesses for 25 $(15.8 \%)$, neurotic illness for $34(21.5 \%)$, personality disorder for $19(12.0 \%)$, and other diagnoses for the remaining $31(19 \cdot 6 \%)$. A further 294 people (an additional 43\%) had a recorded episode of specialist psychiatric care for schizophrenia outside hospital without any record of inpatient care (table 3). Expressed as population based rates, the data show that whichever measure of schizophrenia is used, age specific rates were higher in young adults than in other age groups; higher in males than females up to the age group 35-44 years; and higher in females than males in people aged 45-64 years and older (table 3 ). The all ages incidence of schizophrenia for people with any contact with specialist psychiatric services was 15.1 per 100000 males and 11.4 per 100000 females. The corresponding figures for people aged 15-54 years, cited for comparability with published data on schizophrenia in other populations, ${ }^{1314}$ were 18.9 and 14.6 per 100000 males and females respectively.

PREVALENCE OF TREATED SCHIZOPHRENIA

Including all patients with psychiatric contacts, regardless of the year of first contact, a total of 303 people alive on the "point prevalence" date (31 December 1986) had had at least one contact with specialist psychiatric services in the previous year (table 4). Point prevalence rates were males 63.0 and females 51.8 per 100000 population. A total of 930 people alive on the prevalence date had had at least one contact with specialist care for schizophrenia in the previous five years, representing rates of 188.5 and 163.8 per 100000 males and females respectively. An additional four people in the year previously, and 67 people in the five years previously, had been treated for schizophrenia and had died before the "point prevalence" date.

\section{Discussion}

OBSERVATIONS ON SCHIZOPHRENIA

The incidence of treated schizophrenia, measured as contact with specialist psychiatric services, is influenced by a number of factors. These include the true incidence of schizophrenia in the population; the percentage of people with schizophrenia who seek medical care; the provision of specialist services; and local practice in respect of referral to specialist psychiatric care. Estimates of incidence will also vary according to the diagnostic criteria used. International studies of schizophrenia coordinated by the World Health Organisation, using restricted criterion-based definitions of the disease, found annual incidence rates, per 100000 males and females aged 1554 years, of 17 and 12 in Nottingham, 10 and 8 in Dublin, and 9 and 5 in Aarhus. ${ }^{14} \mathrm{~A}$ broader definition, including all patients with a clinical diagnosis of schizophrenia, yielded rates, per 100000 males and females aged $15-54$ years, of 28 and 15 in Nottingham, 23 and 21 in Dublin, and 18 and 12 in Aarhus. The data in our study, at 19 per 100000 males and 15 per 100000 females aged 15-54 years, were within the range of those reported on the broad definition of the WHO study.

Our data are based on diagnoses recorded in the case notes by psychiatrists. Retrospective validation studies of the psychiatric diagnoses were not carried out but quality controls of form completion and clinical coding, and chasing of missing records, were undertaken routinely at the time of data collection. The only serious problem of known under recording is that there was some under reporting of domiciliary visits, particularly in the early part of the study period. In so far as non-inpatient data were missing, the figures given in this paper underestimate the true frequency of schizophrenia. Our data exclude direct referrals by general practitioners to psychiatric care 
provided by people other than their psychiatrists (such as community psychiatric nurses and psychologists) but such direct referrals were uncommon in this period. We have no way of knowing the extent to which people with schizophrenia were treated solely by their general practitioners without referral to psychiatrists in this period. This is also a source of possible underestimation of schizophrenia in the population studied. The increasing use of computers in general practice to record and analyse information about psychiatric diagnoses and psychiatric care ${ }^{15}$ may enable estimates to be made in future of the extent of psychiatric illness which is managed without specialist psychiatric care.

Trends over time in the treated incidence of schizophrenia show the same general pattern in the Oxfordshire population whether one considers patients with schizophrenia at first recorded psychiatric admission, at any psychiatric admission, or at any contact, although these measures give different absolute numerical values of the treated incidence of schizophrenia. ${ }^{16}$ The pattern of occurrence of schizophrenia by age and sex reported here is similar to that found in other populations. Female rates have been shown to be lower than male rates up to middle age, and higher than male rates thereafter, both at first admission and at first contact. ${ }^{4131417}$ We also confirm that when a diagnosis of schizophrenia is made, it is less likely to be made at the patients' first admission in females than in males. ${ }^{18} \mathrm{We}$ therefore add support to the evidence that the incidence and demographic characteristics of schizophrenia are similar in different populations.

The diagnoses which preceded schizophrenia in our study may represent the natural prodromal course of schizophrenia, a revised clinical view of the diagnosis, or coexisting conditions. Affective psychosis and paranoid states may exhibit overlap with schizophrenia phenomenologically. The consistency of psychiatric diagnoses, and the validity of their change, are fruitful areas for study but would need detailed case by case review.

\section{STRENGTHS AND LIMITATIONS OF ROUTINE} INFORMATION SYSTEMS IN ESTIMATING THE INCIDENCE AND PREVALENCE OF TREATED DISEASE

The strength of routine information systems in providing information about the occurrence of disease is that alternative methods, such as regular population based surveys on sufficient scale, would be very expensive to undertake. We have attempted to quantify the incidence and prevalence of treated schizophrenia as precisely as possible within the limits of our datasets. However, none of the measures currently available from routine statistics is entirely satisfactory. As noted above, "incidence" data on first ever psychiatric admission, with schizophrenia as the diagnosis at the first ever admission, miss people who are first diagnosed as schizophrenic at a later ad- mission. They also miss people who are diagnosed with schizophrenia but who do not receive inpatient care. Our results exclude contacts for anyone who had a psychiatric inpatient admission in the 10 years before estimating first contact rates but, none the less, the first recorded contact for some people may not necessarily have been their first ever psychiatric service contact with the diagnosis. The accurate quantification of incidence, rather than "best approximations" as given here, requires information systems which not only include each diagnosis but which also include the means to identify the date on which each diagnosis was first made for each patient. Because patients may move home, it is also necessary to have the means to identify individuals' place of residence at first diagnosis to calculate incidence rates in relation to defined denominator populations.

Our estimates of prevalence are those for people who had been treated for schizophrenia, a condition with a very variable clinical course, rather than for active schizophrenia itself. The estimates are also limited by the fact that calculation of migration of affected individuals out of the population was not possible. The accurate quantification of prevalence ideally requires information on dates of recovery, or death, and on migration of patients into and out of study populations. These principles apply, of course, not only to information about the incidence of psychiatric disorders but also to information systems concerned with any other chronic or relapsing clinical condition. It is important that these principles are recognised because the increasing availability of computerised statistical data about patient care, in general practice as well as in hospital practice, means that the potential to quantify the occurrence of disease routinely is increasing.

The Unit of Health-Care Epidemiology is funded by the Department of Health and the Oxford Regional Health Authority. We thank Liza Brandon for typing the manuscript.

1 Office of Population Censuses and Surveys. Mental Health Enquiry. London: HMSO. Annual until 1985.

2 Department of Health and Social Security. Steering group on health services information. First report to the secretary of state. (Chairman: Mrs E Korner). London: HMSO, 1982.

3 Department of Health. Working for patients. Framework for information systems: the next steps. London: HMSO, 1990. infor

4 Watt DC, Szulecka TK. The effect of sex, marriage and age at first admission on the hospitalisation of schizophrenia at first admission on the hospitalisation of schizophrenia
during two years following discharge. Psychol Med

5 Hare EH. Aspects of the epidemiology of schizophrenia. $\mathrm{Br}$ f Psychiatry 1986;149:554-61.

6 Stromgren E. Changes in the incidence of schizophrenia? Br F Psychiatry 1987;150:1-7.

7 Kendell RE, Malcolm DE, Adams W. The problem of detecting changes in the incidence of schizophrenia. $\operatorname{Br} f$ Psychiatry 1993;162:212-18.

8 Acheson ED. Medical record linkage. Oxford: Oxford University Press, 1967.

9 Gill LE, Baldwin JA. Methods and technology of record linkage: some practical considerations. In Baldwin JA, Acheson ED, Graham WJ, eds. Textbook of medical record linkage. Oxford: Oxford University Press, 1987:39-54.

10 Baldwin JA. Oxford Record Linkage Study. Psychiatry Information System: manual of instructions and procedures. formation System: manual of instructions and proc

11 World Health Organisation. International classification of diseases. 8th rev. Geneva: World Health Organisation, 1967.

12 World Health Organisation. International classification of diseases. 9th rev. Geneva: World Health Organisation, 1977. 
13 Sartorius N, Jablensky A, Korten A, Ernberg G, Anker M, Cooper JE, Day R. Early manifestations and first-contact incidence of schizophrenia in different cultures. Psychol Med 1986;16:909-28.

14 Jablensky A, Sartorius N, Ernberg G, Anker M, Korten A, Cooper JE, Day R. Schizophrenia: manifestations, incidence and course in different cultures. A World Health Organisation ten country study. Psychol Med 1988; Organisation ten country stud

15 Nazareth I, King M, Haines A, Rangel L, Myers S.
Accuracy of diagnosis of psychosis on general practice computer system. BMF 1993;307:32-4.

16 de Alarcon J, Seagroatt V, Goldacre M. Is schizophrenia declining? Lancet 1990;335:852-3.

17 Loranger AW. Sex differences in age at onset of schizophrenia. Arch Gen Psychiatry 1984;41:157-61.

18 Monk-Jorgensen P. The schizophrenia diagnosis in Denmark. A register-based investigation. Acta Psychiatr Scand 1985;72:266-73. 